\title{
Selenium Concentration and Glutathione Peroxidase Activity in Plasma and Erythrocytes from Human Blood
}

\author{
Tadatoshi YamaguchI, ${ }^{1, *}$ Kinuko UChimura, ${ }^{1}$ Yoshika KuroKawa, ${ }^{2}$ \\ Minoru Hamada, ${ }^{1}$ Kenjiro Inoue, ${ }^{3}$ and Noritoshi SHIBUYA ${ }^{4}$ \\ ${ }^{1}$ Department of Hygiene, Miyazaki Medical College, Kiyotake, \\ Miyazaki 889-16, Japan \\ ${ }^{2}$ Department of Hygiene, Ehime University School of Medicine, \\ Shigenobu, Ehime 791-02, Japan \\ ${ }^{3}$ National Miyazaki Higashi Hospital, \\ Miyazaki 880, Japan \\ ${ }^{4}$ National Kawatana Hospital, Kawatana, \\ Nagasaki 859-36, Japan
}

(Received September 14, 1991)

\begin{abstract}
Summary The concentration of selenium (Se) and the activity of glutathione peroxidase (GSH-Px) in plasma and erythrocytes were measured in healthy men and in patients with Duchenne-type progressive muscular dystrophy (DMD). In healthy men, the Se concentration in erythrocytes showed a steep rise with aging and ascended gradually in plasma. The GSH-Px activity in both plasma and erythrocytes clearly increased with aging. The relationship between the Se concentration and the GSH-Px activity in healthy men showed a parallel rise with aging, but the coefficients of correlation were not very high $(r=0.44$ and 0.56 in plasma and erythrocytes, respectively). In DMD patients, on the other hand, the Se concentration in erythrocytes decreased steeply with aging, and it decreased gradually in plasma. The GSH-Px activity in both plasma and erythrocytes apparently increased as in healthy men with aging, but the level was about $80 \%$ of that of healthy men. These data suggest that a lower GSH-Px activity in DMD patients may explain in part why the disease may intensify with aging.
\end{abstract}

Key Words: selenium concentration, glutathione peroxidase activity, Duchenne-type progressive muscular dystrophy

Although selenium (Se) is recognized as an essential micro-nutrient for certain plants and animals $[1,2]$, little is known of the nutritional requirements

*To whom correspondence should be addressed. 
for it or its physiological functions. The only characterized and essential biochemical function in mammals is its association with the enzyme glutathione peroxidase (GSH-Px, EC 1.11.1.9) [3-5]. The endemic cardiomyopathy known as Keshan disease in China, which occurs mainly in infants and children, was prevented by supplementation of the diet with Se [6]. This element may be essential for function of heart and other muscles in humans. Se deficiency was associated with human diseases such as Kwashiorkor [7,8], sudden death syndrome in infants [9], cancer [10], and multiple sclerosis [11]. The actual relationship between these diseases and Se deficiency is not clear, although Se concentration relating to GSH-Px was discussed in some instances [12-15]. Muscular dystrophy is known to be a consequence of Se deficiency in animals [16-18]. We therefore investigated the relationship between Se and human muscular dystrophy.

As mentioned later, Se content in blood varies widely, depending on various factors such as the Se content of soil (which influences the Se content of foods), dietary intake, age, and furthermore the errors inherent in the various methods of analysis. In the blood of normal adults, people in New Zealand showed the lowest values [19] with $54 \pm 1 \mathrm{ng} / \mathrm{ml}(n=113)$ in whole blood, $66 \pm 3 \mathrm{ng} / \mathrm{ml}(n=109)$ in erythrocytes, and $43 \pm 2 \mathrm{ng} / \mathrm{ml}(n=109)$ in plasma. The highest values were found in the USA [20] with $265 \pm 56 \mathrm{ng} / \mathrm{ml}(n=626)$ in whole blood and in Canada [21] with $142 \pm 16 \mathrm{ng} / \mathrm{ml}(n=15)$ in serum. There are some whole blood data for Japanese, the values for whom range widely: $132 \pm 29 \mathrm{ng} / \mathrm{ml}$ (males, $n=274$ ) and

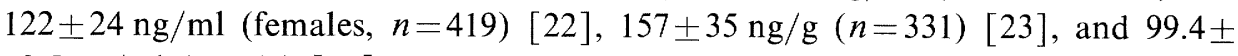
$12.5 \mathrm{ng} / \mathrm{ml}(n=65)$ [24].

The relationship between Se concentration in blood and diseases such as cancer [25] and others [26-29] has been discussed in a number of papers. In this present study, the relationship between Se concentration and GSH-Px activity in blood was examined in healthy Japanese males. The relationship was also examined in the blood from patients with Duchenne-type progressive muscular dystrophy (DMD).

\section{MATERIALS AND METHODS}

Materials. Subjects for Se determination were 72 healthy male Japanese with ages ranging from 7 to 52 years (60\% of this group were between 16 and 18 years old). All of them were living in Miyazaki, Kyushu Island, Japan. The second group consisted of 32 hospitalized DMD patients who were from 9 to 24 years old (Miyazaki and Nagasaki, Kyushu Island, Japan). Blood samples were collected and stored in metal-free tube containing sodium heparinate $(30 \mu 1$ in $10 \mathrm{ml}$ of blood) as an anticoagulant. After centrifugation at $1,000 \times g$ for $10 \mathrm{~min}$ at room temperature, plasma and erythrocytes were separated. The erythrocytes were washed three times with isotonic saline to remove the buffy coat and frozen at $-80^{\circ} \mathrm{C}$ until analyzed.

Reagents. Unless otherwise noted, all were purchased from Wako Pure 
Chemical Industries, Ltd., Osaka. As the standard for Se analysis, the Se solution $(1,000 \mathrm{ppm})$ for atomic absorption analysis was used. For wet-ashing of blood samples, analytical grade acids were used. For the GSH-Px assay, we employed yeast glutathione reductase (Oriental Yeast Co., Osaka) and the reduced form of nicotinamide adenine dinucleotide phosphate (NADPH; Sigma Chemical Co., St. Louis, MO). For the hemoglobin determination, Drabkin's reagent ( $1.0 \mathrm{~g}$ of sodium bicarbonate, $0.05 \mathrm{~g}$ of potassium cyanide, and $0.20 \mathrm{~g}$ of potassium ferricyanide) was dissolved in 1 liter of deionized water before use.

Apparatus. An atomic absorption flame spectrophotometer (AA-620, Shimadzu Co., Kyoto) equipped with an automated vapor generator accessory (VGA-76, Varian Instruments Ltd., Tokyo) was used for determination of Se as hydrogen selenide according to electrothermal atomic absorption methods [30, 31]. For ashing of samples, a rapid digester (SRD-6, Mitamura Riken Kogyo Inc., Tokyo) was used. To determine GSH-Px activity and hemoglobin concentration, we employed a Cary 2290 UV-VIS scanning spectrophotometer (Varian Instruments Ltd., Tokyo) with the temperature of the cell compartment kept at $37^{\circ} \mathrm{C}$ (for the enzyme assay) with circulating water.

Determination of Se concentration. To 300-500 $\mu 1$ of whole blood, plasma, or erythrocytes, $10-15 \mathrm{ml}$ of a mixture of nitric acid and perchloric acid $(5: 1, \mathrm{v} /$ v) was added. Ashing was performed by heating of ca. $15 \mathrm{ml}$ of the sample in a hot air bath for 30-60 min. The ashed solution was diluted to $5 \mathrm{ml}$ in a volumetric flask by addition of deionized water. The sample solution in the flask was passed to the vapor generator together with $10 \mathrm{M}$ hydrochloric acid and $6 \mathrm{~g} /$ liter sodium borohydride in $5 \mathrm{~g} /$ liter sodium hydroxide solution, and then the generated vapor was introduced into the atomic absorption spectrophotometer. Standard solution $(3,5,10,15,20,25,30,35,40,45,50 \mathrm{ppb})$ were made by dilution of a commercially available solution $(1,000 \mathrm{ppm})$ with $1 \mathrm{M}$ nitric acid. Each time after a sample had been run, a standard solution was also measured and the peak height of the former was directly compared with that of the latter to make as small an error as possible. Mean recovery of $100.7 \mathrm{ng} / \mathrm{ml}( \pm 5.0, n=3)$ was obtained for $100 \mathrm{ng} / \mathrm{ml} \mathrm{Se}$ added to whole blood.

Determination of GSH-Px activity. The enzyme assay was performed as previously published [32]. The erythrocytes separated by centrifugation from plasma were hemolyzed by a four-fold dilution with deionized water. The hemolysate was diluted five-fold with Drabkin's reagent, and then the GSH-Px activity was determined. The complete system contained in a total volume of $1 \mathrm{ml}$ the following components: $50 \mathrm{mM}$ Tris- $\mathrm{HCl}$ ( $\mathrm{pH}$ 7.6), $1 \mathrm{mM} \mathrm{Na} \mathrm{N}_{2}$ EDTA, 2 mM reduced glutathione, $0.2 \mathrm{~mm} \mathrm{NADPH}, 4 \mathrm{~mm}$ sodium azide, $1,000 \mathrm{U} /$ liter glutathione reductase, $20 \mu \mathrm{l}$ of hemolysate, and $10 \mu \mathrm{l}$ of $\mathrm{H}_{2} \mathrm{O}_{2}(8.8 \mu \mathrm{M})$. Before addition of the $\mathrm{H}_{2} \mathrm{O}_{2}$, the reaction mixture $(990 \mu 1)$ was incubated for $5 \mathrm{~min}$ at $37^{\circ} \mathrm{C}$ and then the reaction was initiated by addition of the $\mathrm{H}_{2} \mathrm{O}_{2}$ and followed with the decrease in NADPH absorbance at $340 \mathrm{~nm}$ for $3 \mathrm{~min}$. After a $30 \mathrm{~s}$ lag period, the decrease was linear with time. The enzyme activity was calculated from the slope of these lines

Vol. 12, No. 1, 1992 
as $\mu$ mol NADPH oxidized per minute. The nonenzymic reaction rate in the blank was determined by substitution of water for the hemolysate. The enzyme activities were indicated as units/g of hemoglobin $(\mathrm{Hb})$. The $\mathrm{Hb}$ concentration in fourfolddiluted hemolysate was determined by the cyanomethemoglobin method. To determine enzymic activity in plasma, we added $50 \mu 1$ of undiluted plasma to 950 $\mu l$ of the reaction mixture and proceeded as described above. The enzyme activities were given as units/liter of plasma.

\section{RESULTS}

No variation in Se concentration due to diurnal rhythm was observed when blood was sampled every 1.5 h from 7:30 AM to 8:00 PM. Nor was variation due to freeze-storage observed when the samples were stored frozen for various periods from 1 week to 6 months (data not included). The Se concentrations in plasma and erythrocytes of 72 healthy men are shown in Figs. 1 and 2, respectively, expressed as mean $( \pm \mathrm{SD}) \mathrm{ng} / \mathrm{ml}$ for each age bracket: $9-14(n=10), 15-19(n=39), 20-24$ $(n=9)$, and 25-52 $(n=14)$ years of age. The blood samples from the 32 patients

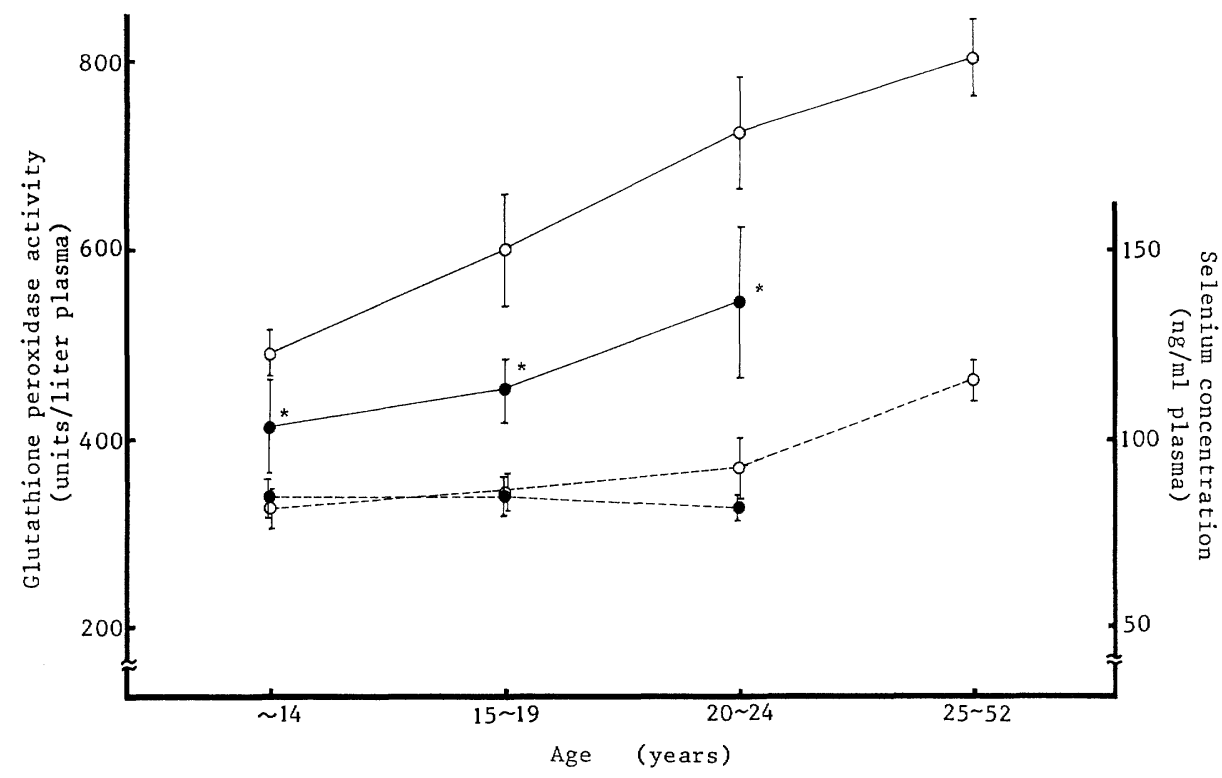

Fig. 1. Selenium (Se) concentration and glutathione peroxidase (GSH-Px) activity in plasma in relation to aging. Values are shown as mean $( \pm S D)$ at four age brackets. Subject numbers were $10,39,9$, and 14 for the Se concentration of healthy men $(\cdots \circ \cdots)$; $8,39,9$, and 6 for the GSH-Px activity of healthy men (-०-);14,14, and 4 for the Se concentration of DMD patients $(\cdots \cdots)$; and 14, 13, and 4 for the GSH-Px activity of DMD patients (- - ) for each respective point from left to right. The values marked with ${ }^{*}$ were significantly lower $(p<0.05)$ than the corresponding ones for GSH-PX activity of the healthy men. 


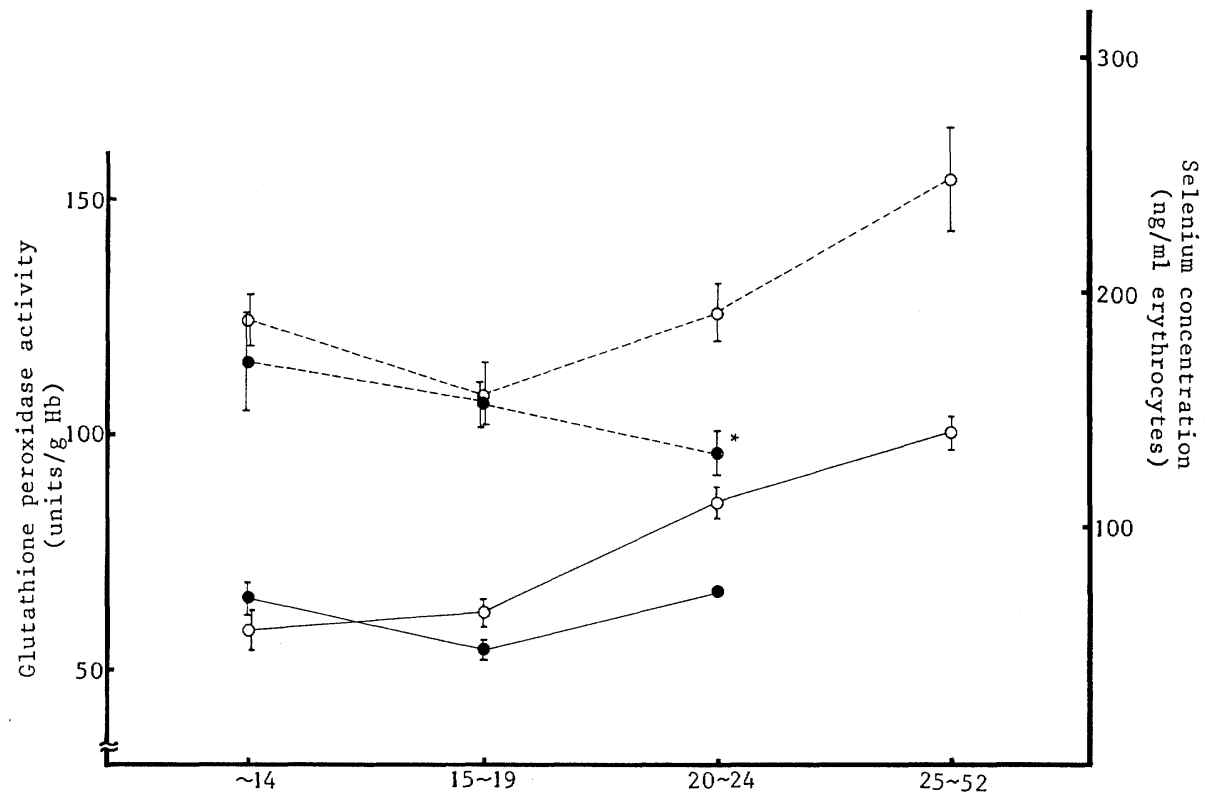

Fig. 2. Selenium (Se) concentration and glutathione peroxidase (GSH-Px) activity in erythrocytes in relation to aging. Values are shown as mean $( \pm \mathrm{SD})$ at four age brackets. Subject numbers were $10,39,9$, and 14 for the Se concentration of healthy men $(\cdots \circ \cdots)$; $2,31,8$, and 6 for the GSH-Px activity of healthy men $\left(-\mathrm{O}_{-}\right) ; 13,14$, and 15 for the Se concentration of DMD patients $(\cdots \cdots)$; and 10, 8, and 1 for the GSH-Px activity of DMD patients (--) for each respective point from left to right. The value marked with * differed significantly $(p<0.05)$ from the corresponding one for Se concentration of the healthy men.

were obtained from the two hospitals in which the men were hospitalized. No difference in Se concentration of food in the two hospitals was inferred from the following results: The values of patients with DMD were $75.1( \pm 13.8) \mathrm{ng} / \mathrm{ml}$ in plasma and $176.9( \pm 45.8) \mathrm{ng} / \mathrm{ml}$ in erythrocytes of the patients $(n=10)$ in the hospital at Miyazaki, and $84.3( \pm 10.0) \mathrm{ng} / \mathrm{ml}$ in plasma and $148.6( \pm 22.7) \mathrm{ng} / \mathrm{ml}$ in erythrocytes of the patients $(n=22)$ in the hospital at Nagasaki. There was no significant difference in the values between samples from these two hospitals. Therefore, the patients of two hospitals were not distinguished in the treatment of data. The Se concentrations of the DMD patients $(n=32)$ are also shown in Figs. 1 and 2 for comparison with those of the healthy men.

For healthy men aged from 7 to 52 years, the mean plasma enzyme activity was $605.5 \pm 128.3$ units/liter $(n=62)$ and mean erythrocyte enzyme activity was $70.9 \pm 18.7$ units/g of $\mathrm{Hb}(n=47)$. On the other hand, for the patients the respective values were $447.6 \pm 109.9$ units/liter $(n=31)$ and $60.3 \pm 11.6$ units/g of $\mathrm{Hb}(n=19)$. The decrements in enzyme activity in plasma and erythrocytes of the DMD patients were 15 and $24 \%$, respectively. For the comparison of Se concentration 


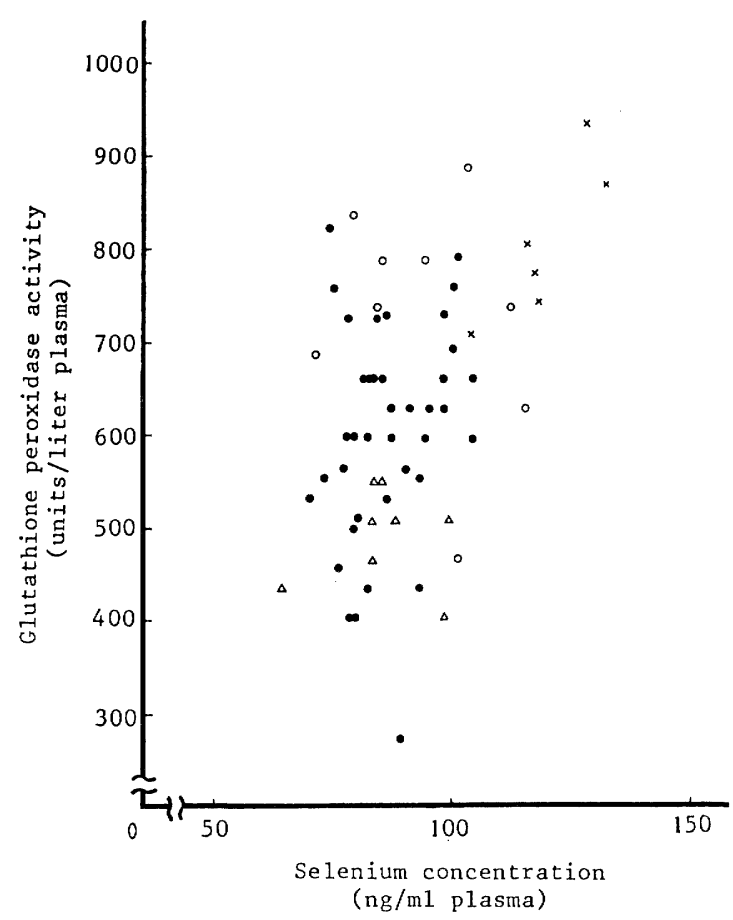

Fig. 3. The correlation between selenium concentrations and glutathione peroxidase activities in plasma of 62 healthy men of different ages. The ages (years) of the subjects are marked by $\triangle, 7-14 ; \bullet, 15-19 ; 0,20-24$; and $\times, 25-52$.

with GSH-Px activity, the patients were grouped in age brackets of 7-14, 15-19, and 20-24 years old. The mean values of GSH-Px activity rose with aging in both of plasma and erythrocytes. The results were summarized in Figs. 1 and 2 with that of healthy men. The distribution of GSH-Px activity in relation to Se concentration in plasma and erythrocytes of healthy men is shown in Figs. 3 and 4 , respectively. The coefficients of correlation in Figs. 3 and 4 were $0.44(p<0.05)$ and $0.56(p<0.05)$, respectively.

\section{DISCUSSION}

The highest Se concentrations were found in the 25-52-year-old group of healthy men, and these values were lower than those found for the corresponding group in the USA [20]. The mean value $(159.1 \pm 14.3 \mathrm{ng} / \mathrm{ml}, n=9)$ for the whole blood in the 20-24-year-old group is a fairly good approximation of the data reported in previous paper $[22,23]$ showing Se concentrations in whole blood of adult Japanese. The values in plasma of children were also in agreement with earlier data [24]. As shown in Fig. 1, the Se concentration in plasma of the normal males increased gradually with age. This increasing trend agrees with data in 


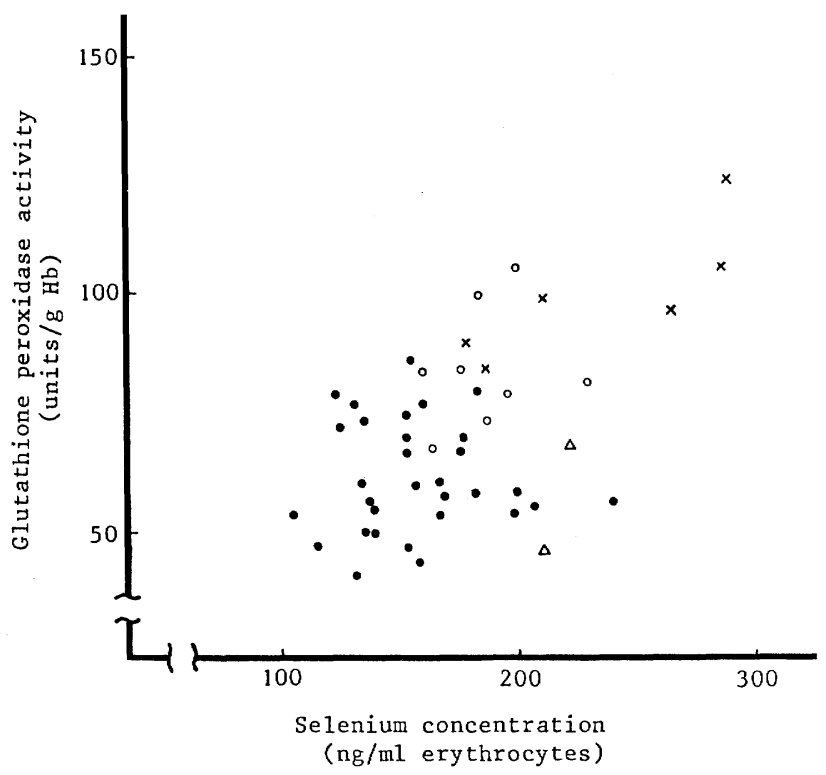

Fig. 4. The correlation between selenium concentrations and glutathione peroxidase activities in erythrocytes of 47 healthy men of different ages. The ages (years) of the subjects are marked by $\triangle, 7-14 ; \bullet, 15-19 ; \bigcirc, 20-24$; and $\times, 25-52$.

earlier paper $[24,33,34]$. The Se concentration in erythrocytes of normal males, which value has apparently not been previously published in relation to aging, increased steeply with age, although the 15-19-year-old group showed a low reading which differed significantly $(p<0.05)$ from values for both $10-14$ and $20-$ 24 age brackets. We suggest that Se concentration in plasma and erythrocytes reflect the physiological requirements of every age bracket. Therefore, the low value for erythrocytes in the 15-19-year-old group may mean that Se is sequestered in other tissues rather than in blood. This is interesting because little is known of the roles of Se in vivo.

It may be better to use as controls non-dystrophic patients who are hospitalized in the same hospital as DMD patients. However, only the plasma from 6 patients (8-14 years old) with infantile asthma or bronchial asthma were obtained $(n=6)$, showing a mean Se concentration in plasma of $72.7 \pm 18.4 \mathrm{ng} / \mathrm{ml}$. This value was not significantly different from that of healthy subjects (9-14 years old, $n=10$ ) who showed a mean Se concentration in plasma of $84.2 \pm 10.2 \mathrm{ng} / \mathrm{ml}$. Therefore, the results obtained from the healthy men would appear to indicate this group to be appropriate as controls.

The contrast between healthy men and patients in terms of Se concentration was more remarkable in erythrocytes (Fig. 2) than in plasma (Fig. 1). The Se values of both plasma and erythrocytes of DMD patients showed a decrease with aging. Especially the decrease in erythrocytes is obvious, contrary to that of healthy men. The values of the 20-24-year-old patients showed a reduction of 25 
and $32 \%$ in plasma and erythrocytes, respectively, in comparison with those of healthy men. The sole value of Se concentration in erythrocytes for the 20 24-year-old group differed significantly $(p<0.05)$ from the corresponding value of the healthy group. As it is well known that DMD intensifies with aging, the relationship between Se concentration and the clinical symptoms would appear to be inversely proportional. In a paper [19] referring to Se deficiency in total parenteral nutrition (TNP), the authors described that the Se concentration in plasma of the patient receiving TNP is influenced more considerably than that in erythrocytes. This means that the Se concentration in erythrocytes is affected only in the case of prolonged Se deficiency, while the Se deficiency in plasma is distinguishable early. In papers [35-37] describing electron spin resonance studies of erythrocytes from patients with DMD, abnormality of the red cell membrane is discussed. Consequently, our results lead us to the following hypothesis: The membrane of the DMD red cell becomes progressively abnormal in its permeability toward Se; and, thereby, the transport of Se from plasma into erythrocytes is inhibited. This view is in line with our finding that Se decrement in erythrocytes of the patients was more pronounced than that in plasma. Further experiments should be carried out in order to verify the abnormality of the red cell membrane.

The role of Se in vivo is little known. We took notice of the enzyme glutathione peroxidase (GSH-Px) in which Se is a component. This enzyme may play a definitive role in protection from lipid peroxide-initiated damage of tissues. Two enzymes having GSH-Px activity were reported already [38, 39]. One depends on $\mathrm{Se}$ and reacts with $\mathrm{H}_{2} \mathrm{O}_{2}$ as substrate. The other one does not depend on Se and can not react with $\mathrm{H}_{2} \mathrm{O}_{2}$. GSH-Px activity of the Se-dependent enzyme was measured by use of $\mathrm{H}_{2} \mathrm{O}_{2}$, and then the relationship between Se concentration and GSH-Px activity was investigated. On the GSH-Px activity of healthy men, the tendency toward an increase in activity with aging in both of plasma and erythrocytes supports a report on age-related changes in the enzyme activity in rat liver [40]. The results shown in Figs. 1 and 2 demonstrated that the Se concentration and the GSH-Px activity of healthy men seemed visibly to be parallel, but the correlation between the two was very low. On the other hand, the GSH-Px activity in plasma and erythrocytes of the patients with DMD increased with aging, although the activity was ca. $20 \%$ lower than that of healthy men. The values of GSH-Px activity at every age bracket in plasma differed significantly $(p<0.05)$ from the corresponding values for healthy men. Figures 1 and 2 showed the mutual relation among Se concentration, GSH-Px activity, and age bracket in plasma and erythrocytes. The differences between healthy men and patients were clearly indicated in the 20-24-year-old group. It is not known now whether the state of the patients in the 20-24-year-age bracket is due to the disease or is a result of it. We speculate that the lowering of the GSH-Px activity in plasma of the patients resulted in part from the DMD disease process.

We are greatly indebted to Drs. Y. Itokawa, M. Kimura, and K. Sekine (Dept. of Hygiene, 
Faculty of Medicine, Kyoto University) for their kind instruction on atomic absorption spectrometry analysis. We also thanks Dr. T. Okishima (Dept. of Pediatrics, Miyazaki Medical College Hospital) for his kind provision of the blood samples from healthy children.

\section{REFERENCES}

1. Scott, M.L. (1973): The selenium dilemma. J. Nutr., 103, 803-813.

2. Schwarz, K., and Foltz, C.M. (1957): Selenium as integral par of factor 3 against dietary neucrotic liver degeneration. J. Am. Chem. Soc., 79, 3292-3293.

3. Rotruck, J.T., Pope, A.L., Ganther, H.E., Swanson, A.B., Hafeman, D.G., and Hoekstra, W.G. (1973): Selenium: Biochemical role as a component of glutathione peroxidase. Science, 179, 588-590.

4. Flohe, L., Gunzler, W.A., and Schock, H.H. (1973): Glutathione peroxidase: A selenoenzyme. FEBS Lett., 32, 132-134.

5. Nakamura, W., Hosoda, S., and Hayashi, K. (1974): Purification and properties of rat liver glutathione peroxidase. Biochim. Biophys. Acta, 385, 251-261.

6. Chen, X., Yang, X., Chen, J., Chen, X., Wen, Z., and Ge, K. (1980): Studies on the relations of selenium and Keshan disease. Biol. Trace Element Res., 2, 91-107.

7. Schwarz, K. (1965): Selenium and Kwashiorkor. Lancet, 1, 1335-1336.

8. Burk, R.F., Jr., Pearson, W.N., Wood, R.P., and Viteki, F. (1967): Blood selenium levels and in vitro red blood cell uptake of ${ }^{75} \mathrm{Se}$ in Kwashiorkor. Am. J. Clin. Nutr., 20, 723-733.

9. Money, D.F.L. (1970): Vitamin E and selenium deficiencies and their possible aetiological role in the sudden death in infants syndrome. N.Z. Med. J., 71, 32-34.

10. Shamberger, R.J., and Willis, C.E. (1971): Selenium distribution and human cancer mortality. CRC Crit. Rev. Clin. Lab. Sci., 2, 211-221.

11. Wikstrom, J.T., and Westesmark, P.J. (1976): Selenium, vitamin E and copper in multiple sclerosis. Acta Neurol. Scand., 54, 287-290.

12. Jensen, G.E., Nirlsen, G.G., and Clausen, J. (1980): Leucocyte glutathione peroxidase activity and selenium level in multiple sclerosis. J. Neurol. Sci., 48, 61-67.

13. Agstoni, A., Gerli, C.G., Beretta, L., Palazzini, G., Buso, G.P., Xusheng, H., and Moschini, G. (1983): Erythrocyte antioxidant enzymes and selenium serum levels in an Andean population. Clin. Chim. Acta, 133, 153-157.

14. Goodwin, W.J., Jr., Lane, H.W., Bradford, K., Marshall, M.V., Griffin, A.C., Geopfert, H., and Jesse, R.H. (1983): Selenium and glutathione peroxidase levels in patients with epidermoid carcinoma of the oral cavity and oropharynx. Cancer, 51, 110-115.

15. Ward, K.P., Arthur, J.R., Russell, G., and Aggett, P.J. (1984): Blood selenium content and glutathione peroxidase, asthma, and epilepsy. Eur. J. Pediatr., 142, 21-24.

16. Brown, R.G., Sweeny, P.R., George, J.C., Stanley, D.W., and Moran, E.T., Jr. (1974): Selenium deficiency in the duck: Serum ascorbic acid levels in developing muscular dystrophy. Poult. Sci., 53, 1235-1239.

17. Muth, O.H., Oldfield, J.E., Remmert, L.F., and Schudert, J.R. (1958): Effects of selenium and vitamin E on white muscle disease. Science, 28, 1090.

18. McLean, J.W., Thomson, G.G., and Claxton, J.H. (1959): Growth responses to selenium in lambs. Nature, 184, 251-252.

19. van Rij, A.M., Thomson, C.D., McKenzie, J.M., and Robinson, M.F. (1979): Selenium deficiency in total parenteral nutrition. Am. J. Clin. Nutr., 32, 2076-2085.

20. Howe, S.M. (1979): Selenium in the blood of South Dakotans. Arch. Environ. Health, 34, 444-448.

21. Lalonde, L., Jean, Y., Roberts, K.D., Chapdelaine, A., and Bleau, G. (1982): Fluorometry of selenium in serum or urine. Clin. Chem., 28, 172-174.

22. Deguchi, Y. (1985): Relationships between blood selenium concentrations and grasping power, blood pressure, hematocrit, and hemoglobin concentrations in Japanese rural residents. Jpn. J. Hyg., 39, 924-929. 
23. Seki, H. (1987): Influence of selenium on human health. Part 1. Sex difference and change of normal values with increasing age. Jpn. J. Hyg., 42, 947-953.

24. Hatano, S., Nishi, Y., and Usui, T. (1984): Plasma selenium concentration in healthy Japanese children and adults determined by flameless atomic absorption spectrophotometry. J. Pediatr. Gastroenterol. Nutr., 3, 426-431.

25. Hocman, G. (1988): Chemoprevention of cancer: Selenium. Int. J. Biochem., 20, 123-132.

26. Oster, O., Prellwitz, W., Kasper, W., and Meinertz, T. (1983): Congestive cardiomyopathy and the selenium content of serum. Clin. Acta, 128, 125-132.

27. Valimaki, M.J., Harju, K.J., and Ylikahri, H. (1983): Decreased serum selenium in alcoholics-A consequence of liver dysfunction. Clin. Chim. Acta, 130, 291-296.

28. Moore, J.A., Noiva, R., and Wells, I.C. (1984): Selenium concentrations in plasma of patients with arteriographically defined coronary atherosclerosis. Clin. Chem., 30, 171-173.

29. Anneren, G., Gebre-Medhin, M., Gustavson, K.H., and Plantin, L.O. (1985): Selenium in plasma and erythrocytes in patients with Down's syndrome and healthy controls. Acta Paediatr. Scand., 74, 508-514.

30. Cox, D.H., and Bibb, A.E. (1981): Hydrogen selenide evolution-electrothermal atomic absorption method for determining nanogram levels of total selenium. J. Assoc. Off. Anal. Chem., 64, 265-269.

31. Sekine, K., Kimura, M., and Itokawa, Y. (1984): Method for the determination of selenium in biological samples by hydrogen selenide evolution electrothermal atomic absorption. Jpn. J. Hyg., 39, 807-811.

32. Pleban, P.A., Munyani, A., and Beachum, J. (1982): Determination of selenium concentration and glutathione peroxidase activity in plasma and erythrocytes. Clin. Chem., 28, 311316.

33. van Caillie-Bertrand, M., Degenhart, H.J., and Fernandes, J. (1986): Influence of age on the selenium status in Belgium and The Netherlands. Pediatr. Res., 20, 574-576.

34. Lombeck, L., Kasperek, K., Harbisch, H.D., Feinendegen, L.E., and Bremer, H.J. (1977): The selenium state of healthy children. Eur. J. Pediatr., 25, 81-88.

35. Butterfield, D.A., Chesnut, D.B., Appel, S.H., and Roses, A.D. (1976): Spin label study of erythrocyte membrane fluidity in myotonic and Duchenne muscular dystrophy and congenital myotonia. Nature, 263, 159-161.

36. Wilkerson, L.S., Perkins, R.C., Roelofs, R., Swift, L., Dalton, L.R., and Park, J.H. (1978): Erythrocyte membrane abnormalities in Duchenne muscular dystrophy monitored by saturation transfer electron paramagnetic resonance spectroscopy. Proc. Natl. Acad. Sci. U.S.A., 75, 834-841.

37. Sato, B., Nishikida, K., Samuels, L.T., and Tyler, F.H. (1978): Electron spin resonance studies of erythrocytes from patients with Duchenne muscular dystrophy. J. Clin. Invert., 61, 251-259.

38. Lawrence, R.A., and Burk, R.F. (1976): Glutathione peroxidase activity in seleniumdeficient rat liver. Biochem. Biophys. Res. Commun., 71, 952-958.

39. Burk, R.F., Nishiki, K., Lawrence, R.A., and Chance, B. (1978): Peroxide removal by selenium-dependent and selenium-independent glutathione peroxidase in hemoglobin-free perfused rat liver. J. Biol. Chem., 253, 43-46.

40. Pinto, R.E., and Bartley, W. (1969): The effect of age and sex on glutathione in rat homogenates. Biochem. J., 112, 109-112. 